\title{
HIGH-TEMPERATURE HEAT PUMP INTEGRATION INTO DISTRICT HEATING SYSTEM
}

\author{
Ludmila Jakovleva \\ Riga Technical University, Latvia \\ milla.jakovleva@hotmail.com
}

\begin{abstract}
The replacement of fossil fuel-fired boilers for high-temperature water and steam production is very important to increase the efficiency of the energy supply system. High-temperature heat pumps are considered to be a good technology to produce heat, as well as efficiently recover low-grade waste heat from various processes, thus reducing energy consumption and $\mathrm{CO}_{2}$ emissions. Flexible integration of a high-temperature heat pump into heating systems has been recognized as an important step towards a 100\% renewable energy system by converting electrical energy into heat. This paper compiled up-to-date scientific articles on the types of high-temperature heat pumps, options of usage, and advantages. High-temperature heat pumps' cycles, such as single-stage cycle, singlestage cycle with internal heat exchanger, two-stage cycle, two-stage cycle with internal heat exchanger, and twostage cycle with intermediate internal heat exchanger, were viewed, the most appropriate cycles for different temperature increase values were defined. Also, attention was paid to refrigerants, their types, usage limitations, and appropriate choices. The possibility of using high-temperature heat pumps in Latvian district heating systems was evaluated - reduction of the return temperature of the heating system and increase of the supply temperature in order to ensure the system's operation under the low-temperature graph, thus improving the overall system efficiency.
\end{abstract}

Keywords: heating, district, efficiency, recovery.

\section{Introduction}

In the recent years, with the widely discussed issue of reducing greenhouse gas emissions from fossil fuel energy supply sources, the use of renewable energy sources in energy production has become increasingly important. Currently, following the European Union Directive (Directive No. 2018/2001 of the European Parliament and the Council), the Republic of Latvia is actively promoting the usage of energy from renewable energy sources. For energy and heat energy production the usage of wood chips, straw, and biogas is growing significantly, as well as non-traditional renewable energy sources are promoted - heat pumps, solar collectors, solar panels, and wind generators. The main priorities of state energy policy are to support the development of renewable and non-traditional energy sources and to increase the efficiency of the existing energy supply system. Focusing on these priorities will enable Latvia to move to the 4th generation district heating, thus increasing the country's independence from fuel prices, reducing harmful emissions, and ensuring energy savings and effective usage of the system.

The 4th generation district heating presupposes to supply heat at much lower temperatures, thus reducing heat loss, construction materials costs, and allowing the integration of additional heat sources into the district heating system. But according to standard requirements, the temperature of hot water supplied to the consumer should not be lower than 55 degrees Celsius. A high-temperature heat pump allows to solve this problem by increasing the temperature in supply pipeline, while heat with lower parameters can be used in other systems, which, in turn, allows to use all sources of low-temperature heat.

The attempts to introduce high-temperature heat pumps (hereinafter - HTHP) have attracted significant attention for heat production and waste heat recovery, as these devices reduce dependence on fossil fuels, promoting a decarbonized and sustainable industry [1].

Generally speaking, closed heat pump systems can be divided into vapor compression heat pumps, absorption heat pumps, and adsorption heat pumps, which are completely different in operating principles. However, compared to absorption and adsorption heat pumps, vapor compression heat pumps are the most widely used and available in different sizes for different industrial applications [2]. Only vapor compression heat pumps will be considered in this paper.

Unlike conventional heat pumps, which have already gained popularity in the household sector, high-temperature heat pumps are not yet so widespread, as the solutions currently available on the market are mainly limited to use at relatively low temperatures [3]. Generally speaking, vapor compression heat pumps can be classified as conventional heat pumps (HP), high-temperature heat pumps (HTHP), and very high-temperature heat pumps (VHTHP) based on their heat source and 
temperature variability. HTHP can output heat between $80^{\circ} \mathrm{C}$ and $100{ }^{\circ} \mathrm{C}$ with the heat source between $40{ }^{\circ} \mathrm{C}$ to $60^{\circ} \mathrm{C}$, and VHTHP can satisfy heat supply temperatures over $100{ }^{\circ} \mathrm{C}$ with the heat source between $60{ }^{\circ} \mathrm{C}$ and $120^{\circ} \mathrm{C}[4]$.

The ability to "lift" temperature is an important parameter to classify HTHP. It is defined as the difference between the source and output temperature and has a large effect on the coefficient of performance (hereinafter - COP) [4]. From the energetic point of view, exactly COP is the most commonly used indicator to evaluate the efficiency of a heat pump system [5]. If the HTHP's COP is not high enough, heat recovery does not compensate the additional electricity consumption, and the energy efficiency of the proposed system is worse than in conventional cogeneration and trigeneration systems. [6].

Five vapor compression architectures are considered to provide a customized solution to provide useful heat from different grades of industrial waste heat: single-stage cycle, single-stage cycle with internal heat exchanger, two-stage cycle, two-stage cycle with internal heat exchanger, and two-stage cycle with intermediate internal heat exchanger. Paying attention to the selection of the most optimal high-temperature heat pump configuration (architecture), in research made in [1] and [6] it was concluded that for increase temperature of $40 \mathrm{~K}$ single-stage cycle with an internal heat exchanger has a higher performance than other configurations. For a temperature increase of 80-100 K two-stage cycle with internal heat exchangers is considered the best solution $[1 ; 6]$. It is worth noting, that the singlestage cycle, single-stage cycle with an internal heat exchanger, and two-stage cycle are considered to be the most common technologies for nowadays on the market available high-temperature heat pumps with the heat sink temperature up to $165^{\circ} \mathrm{C}$ and the heating capacity up to $20 \mathrm{MW}$.

HTHPs, based on vapor compression technology, typically use hydrofluorocarbons as working fluids (refrigerants), which have high global warming potential values. However, in 2014, EU Regulation No. 517/2014 progressively restricted the production and use of hydrofluorocarbons. Because of this situation, hydrofluorocarbons are being replaced by so-called fourth-generation refrigerants [8]. Hydrofluorofluorefins (HFO), hydrochlorofluoroolefins (HCFO), and natural refrigerants become possible alternatives to replace hydrofluorocarbons (HFC) [1]. It is important to note that the use of HTHP for the heat production and recovery of waste heat using working fluids with a low global warming potential (environmentally friendly working fluids) is a solution to mitigating even more climate change by improving the energy efficiency of industrial processes.

This paper aims to investigate the possibility of integration of the HTHPs into the district heating system and to evaluate such system viability from an economic performance point of view to ensure district heating system operation under the low-temperature graph (the 4th generation district heating).

\section{Materials and methods}

The theoretical assessment of the possibility of using a high-temperature heat pump in district heating systems was made. The district heating system of the city of Riga was taken as an example. The possibility to use high-temperature heat pumps in the district heating system is considered as a possible way to enhance the total energy efficiency of the system.

The natural gas-fired boiler of the considered boiler house provides the power output $2 \mathrm{MW}$ with supply (T1) and return (T2) temperatures respectively 110 and 49 degrees Celsius (ambient air temperature $-20^{\circ} \mathrm{C}$ ). One branch of this district heating grid is transformed to work in accordance with a low-temperature graph. This is accomplished by the usage of a mixing pump, which allows to reach supply/return temperatures of $47^{\circ} \mathrm{C} / 29^{\circ} \mathrm{C}$. A high-temperature heat pump is installed near the consumers and ensures the temperature increase in the supply pipeline by using water heat from the return pipeline from $47^{\circ} \mathrm{C}$ to $65^{\circ} \mathrm{C}$, which is necessary for heating hot water to standard parameters and reducing the risk of Legionella. Thus, the temperature of the return pipeline is reduced from $47^{\circ} \mathrm{C}$ to $29^{\circ} \mathrm{C}$.

At the mixing point of the return water flow from the branch with reduced temperature graph with the return water flow of the branch with a normal temperature graph the temperature of the return water flow at the inlet to the boiler house is equal to $49^{\circ} \mathrm{C}$. The heat load of each branch is $1 \mathrm{MW}$ at the ambient air temperature of $-20^{\circ} \mathrm{C}$. 
The low-temperature district heating system ensures a decrease in heat energy loss for the transportation of the heat-transfer agent from the boiler house to the consumers, so the overall heat energy transfer becomes more efficient, as well as increases the thermal plant (boiler house) performance.

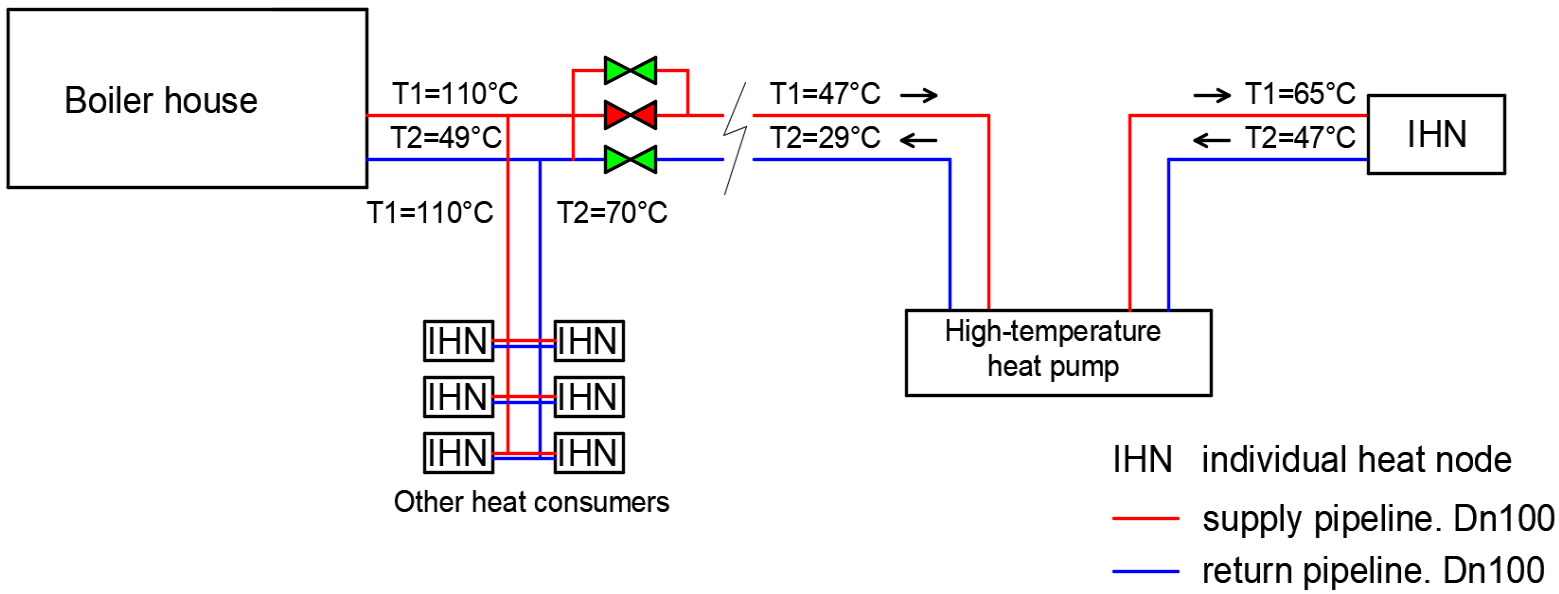

Fig. 1. Schematic of integration of high-temperature heat pump into the district heating system

To determine the viability of this scheme, the reduction of heat loss was defined by calculating it for DN100 pipeline with a second series of insulation (underground channelless laying) and total length of $1 \mathrm{~km}$ for a standard temperature graph, and then for a low-temperature graph. The resulting difference converted into a monetary equivalent (cost of heat energy per $1 \mathrm{MWh}$ ), was compared with the cost of electrical energy consumed by the heat pump to ensure the temperature increase by 18 degrees Celsius (from $47^{\circ} \mathrm{C}$ to $65^{\circ} \mathrm{C}$ ). The theoretical calculations of heat loss were made according to the data of the pipe manufacturer in accordance with two temperature graphs of the district heating system (standard $T 1=110^{\circ} \mathrm{C}, T 2=70^{\circ} \mathrm{C}$; low-temperature $-T 1=47^{\circ} \mathrm{C}, T 2=29^{\circ} \mathrm{C}$; ambient air temperature $-20^{\circ} \mathrm{C}$ ) and soil temperature equal to $4^{\circ} \mathrm{C}$.

$$
N=K\left(T 1+T 2-2 T_{\text {soil }}\right) \cdot L / 1000
$$

where $N$-heat loss, $\mathrm{kW}$;

$K$ - specific heat loss coefficient, $\mathrm{W} \cdot\left(\mathrm{m}^{\circ} \mathrm{K}\right)^{-1}$;

$T 1$ - supply temperature, ${ }^{\circ} \mathrm{C}$;

$T 2$ - return temperature, ${ }^{\circ} \mathrm{C}$;

$T_{\text {soil }}$ - soul temperature, ${ }^{\circ} \mathrm{C}$;

$L$ - heating system length, $\mathrm{m}$.

Viessmann VITOCAL 350-HT PRO heat pump is considered as an appropriate high-temperature heat pump for the described system. This heat pump has the heat capacity from 148 to $390 \mathrm{~kW}$ and COP till 3,4 with the heat source temperature $50^{\circ} \mathrm{C}$ and the ability to raise it till $90^{\circ} \mathrm{C}$ (temperature increase $40 \mathrm{~K}$ ). The heat pump is working with refrigerant R1234ze(E) (type - Hydrofluoroolefins), which is classified as the 4th generation (environmentally friendly, with Ozone Depletion Potential equal to 0 and Global Worming potential < 1) refrigerant with $T_{c}=109.4^{\circ} \mathrm{C}$ and $p_{c}=36,4 \mathrm{bar}$. To achieve higher heating capacity, in the construction of this heat pump, several (2-3) parallel-connected piston compressors are used. As well as the internal heat exchanger is integrated to provide sufficient overheating of the working fluid in the suction line upstream of the compressor (vapor compression architecture - single-stage cycle with internal heat exchanger).

Two types of Viessmann VITOCAL 350-HT PRO heat pumps are considered in this paperBW353.AHT147 and BW353.AHT071.

\section{Results and discussion}

This section includes the results and discussion of the HTHP integration into the district heating system. 
The reduction in heat loss of the described district heating system working in accordance with a low-temperature graph $\left(47^{\circ} \mathrm{C} / 29^{\circ} \mathrm{C}\right)$ is equal to $22.464 \mathrm{~kW}$.

The selected Viessmann VITOCAL 350-HT PRO heat pumps with a temperature increase of $18{ }^{\circ} \mathrm{C}$ (from $47^{\circ} \mathrm{C}$ to $65^{\circ} \mathrm{C}$ ) have heating outputs respectively $496.8 \mathrm{~kW}$ and $249.6 \mathrm{~kW}$. In order to provide the required heat load, it is necessary to install 2 units of BW353.AHT147 and 4 units of BW353.AHT071. The total power consumption of 2 units of BW353.AHT147 is equal to $80.7 \mathrm{~kW}$ and 4 units of BW353.AHT071 consume $75.8 \mathrm{~kW}$ of electrical power.

Considering up-to-date prices for heat energy and electrical energy - $44.10 \mathrm{EUR} \cdot \mathrm{MWh}^{-1}$ and 150.53 EUR. $\mathrm{MWh}^{-1}$ respectively, it is clear that in order to receive a competitive advantage from hightemperature heat pump technology it is necessary that the heat pump's usage of electrical energy (from "Latvenergo" JSC or other sources) is approx.12 times smaller than compensated heat loss. Only these conditions provide economic efficiency of the heat pump, considering the amortization and maintenance costs of the equipment. Taking into account current prices for electricity and heat, this condition is a must to provide an economic benefit of the heat pump integration into the district heating system.

In the described system the consumption of the electrical energy from the city's electrical grid should not exceed $6.58 \mathrm{~kW}$. As for the rest of the electrical power needed alternative sources of electrical energy should be considered as an option, such as solar panels (photoelectric modules) and wind generators. This interconnected system - HTHP + alternative sources of electrical energy, requires further investigation of its benefits.

Taking into account HTHPs prices, installation, maintenance expenses (145000 EUR and 170000 EUR respectively), annual operating time ( $4800 \mathrm{~h}$ during the heating period) and heat loss reduction savings, the payback period of both proposed solutions ( 2 units of BW353.AHT147 and 4 units of BW353.AHT071) is 30.5 years and 36 years respectively, which is significantly longer than the useful life of HTHP systems (20 years).

\section{Conclusions}

1. Within the framework of this paper, the possibility to use high-temperature heat pumps to recover waste heat from different types of processes was considered, thus improving energy efficiency, and reducing the use of fossil fuels.

2. The HTHPs have the potential for reducing heat loss in the heating system and improving the efficiency of heat energy transportation. They can be used to reduce the return temperature of the heating system and to increase the supply temperature, thus allowing the district heating system to work under a low-temperature graph and improving the efficiency of the whole system. But before deciding on the use of the high-temperature heat pump, the ratio of HTHP electrical energy consumption from the city's electrical grid and heat loss coverage must be considered. Alternative sources of electrical energy should be considered as a component of the high-temperature pump system.

3. The payback period of currently available HTHPs exceeds the average useful life of the system. So, it is not economically effective to use HTHP without any financial support from governmental institutions and investment projects. Considering the evolvement of the HTHP technologies due to the development of low-temperature heating systems, the prices for such pumps will significantly decrease, which will reduce the payback period, thus allowing to use them more widely in district heating systems.

4. The integration of HTHP into the district heating system presents a way to enhance the performance for the system of the 4th generation, as well as is an innovative system solution for the decarbonization of various sectors.

\section{Reference}

[1] Mateu-Royo C., Navarro-Esbrí J., Mota-Babiloni A., Amat-Albuixech M., Molés F. Theoretical evaluation of different high-temperature heat pump configurations for low-grade waste heat recovery. International Journal of Refrigeration, vol. 90, 2018, pp. 229-237.

[2] Wu D., Jiang J., Hu B., Wang R.Z. Experimental investigation on the performance of a very hightemperature heat pump with water refrigerant. Energy, vol. 190, 2020, 9 p. 
[3] Bergamini R., Jensen J.K., Elmegaard B. Thermodynamic competitiveness of high-temperature vapor compression heat pumps for boiler substitution. Energy, vol. 182, 2019, pp. 110-121.

[4] Arpagaus C., Bless F., Uhlmann M., Schiffmann J. Bertsch S. High-temperature heat pumps: Market overview, state of the art, research status, refrigerants, and application potentials. Energy, vol. 152, 2018, pp. 985-1010.

[5] Urbanuccia L., Brunob J.C., Testia D. Thermodynamic and economic analysis of the integration of high-temperature heat pumps in trigeneration systems. Applied Energy, vol. 238, 2019, pp. 516533.

[6] Cao X., Yang W.-W., Zhou F., He Y.-L. Performance analysis of different high-temperature heat pump systems for low-grade waste heat recovery. Applied Thermal Engineering, vol. 71, 2014, pp. 291-300.

[7] Kosmadakis G. Estimating the potential of industrial (high-temperature) heat pumps for exploiting waste heat in EU industries. Applied Thermal Engineering, vol. 156, 2019, pp. 287-298.

[8] Mateu-Royoa C., Sawalhab S., Mota-Babilonia A., Navarro-Esbría J. High-temperature heat pump integration into district heating network. Energy Conversion and Management, vol. 210, 2020, 12 p. 